\title{
ROLE OF PROTEINS IN HEALTHY AGEING
}

Alison IC Donaldson ${ }^{1}$, Alexandra M Johnstone ${ }^{2}$, Baukje de Roos ${ }^{2}$, Phyo K Myint ${ }^{1}$

1. Ageing Clinical \& Experimental Research Team, Institute of Applied Health Sciences, University of Aberdeen, Aberdeen, AB25 2ZD, Scotland, UK.

2. The Rowett Institute, University of Aberdeen, Aberdeen, AB25 2ZD, Scotland, UK.

Dr Alison I C Donaldson

SCREDS Clinical Lecturer in Geriatric Medicine

Professor Alexandra M Johnstone

Appetite Research Programme Lead

Professor Baukje de Roos

Deputy Director the Rowett Institute

Professor Phyo K Myint

Professor of Medicine of Old age

Correspondence to: Dr Alison I C Donaldson, Room 1.130. Polwarth Building, Foresterhill, Aberdeen, AB25 2ZD

Tel: +44 (0) 1224 437963, Fax: +44 (0) 1224437911

Mail to: alison.donaldson@abdn.ac.uk 
With the global increase in ageing populations, a current and future key challenge is to improve health expectancy. It is well established that normal ageing is associated with a loss of muscle mass (sarcopenia), with concomitant loss of muscle function and increased risk of falls, reduced ability to perform daily tasks and subsequent reduced quality of life. Therefore, a balanced and optimal protein-energy homeostasis is recognised as a major dietary-related determinant of healthy ageing. This short article provides an overview of the current evidence relating to protein intake in older adults.

Older adults may benefit from a protein intake above the recommended daily allowance, with an intake of $\geq 1.2 \mathrm{~g} / \mathrm{kg} /$ day to help prevent age-related sarcopenia. The failure of older people to adequately regulate food and nutrient intake results in weight loss, and such changes have been term the anorexia of ageing and have been attributed to multiple factors affecting the satiety cascade. The quality and timing of protein supplementation in addition to quantity is very important. To improve muscle protein synthesis, pulse feeding may be more effective than bolus feeding, but further evidence is needed. Key foci of ongoing research should be to provide robust evidence from trials in older adults to help define the optimum type and timing of dietary protein supplements. 
With the global increase in ageing populations, a current and future key challenge is to improve health expectancy. Despite the overwhelming evidence for the role of diet in health, malnutrition (specifically undernutrition) is highly prevalent among older people in the UK; affecting approximately $12-14 \%$ of those who are community-dwelling, and 35\% of those who are institutionalized. ${ }^{1}$ Further, it is well established that normal ageing is associated with a loss of muscle mass (sarcopenia) of $0.5-2 \%$ per year and that the prevalence of sarcopenia is between 4.6 and $7.9 \%$ in community dwelling older British men and women. ${ }^{2}$ The loss of muscle mass has many unwanted consequences related to the role of skeletal muscle as a protein store and the primary site of glucose disposal. ${ }^{3}$ However, the main problem associated with the loss of muscle mass in ageing is the concomitant loss of muscle function, termed dynapaenia. This loss of muscle function and quality increases the likelihood of falls, reduces the ability to perform daily tasks (e.g. rising from a chair) and reduces quality of life. Therefore, a balanced and optimal protein-energy homeostasis is recognised as a major dietary-related determinant of healthy ageing.

This short article provides an overview of the current evidence relating to protein intake in older adults, including the effect of protein on appetite, and the effects of different protein types and timing of ingestion on muscle protein synthesis.

\section{PROTEIN AND ENERGY REQUIREMENTS FOR OLDER ADULTS}

UK recommendations suggested that energy needs of individuals above 60 years are around 1.5 times resting energy expenditure with adaptation for physical activity (i.e. close to $30 \mathrm{kcal} / \mathrm{kg} / \mathrm{day})^{4,5}$ The recommended protein consumption, as promulgated by the World Health Organization (WHO) is $0.8 \mathrm{~g} / \mathrm{kg} /$ day for adults, regardless of age. ${ }^{6}$ However, a number of studies have found that that intake exceeding the Recommended Daily Allowance (RDA) may be preferential in preserving muscle mass and functions in ageing adults. ${ }^{7-11}$ One of the longest 14-week interventional studies to date revealed that in adults aged 55-77, ingestion of $0.8 \mathrm{~g}$ 
protein/kg was associated with decreased mid-thigh muscle area and decreased urinary nitrogen excretion, suggesting that the current RDA might be below the actual requirements of an ageing adult. ${ }^{7}$ This link between protein consumption at the RDA level and adverse health outcomes was also confirmed in a longitudinal observational study by Houston et al ${ }^{12}$; they showed that older adults (70-79 y) whose daily protein intake was $1.1 \pm 0.4 \mathrm{~g} / \mathrm{kg} / \mathrm{bw}$ had lost $40 \%$ less lean body mass over the course of three years than those who consumed $0.8 \pm 0.3$ $\mathrm{g} / \mathrm{kg} / \mathrm{bw} .^{12}$

These higher protein requirements in older adults may be attributed to anabolic resistance, sedentary lifestyles, and high burden of chronic disease, and therefore it has been suggested that older adults need a protein intakes of $\geq 1.2 \mathrm{~g} / \mathrm{kg} /$ day to help prevent age-related sarcopenia. ${ }^{11}$ In spite of these nutrient recommendations, food and meal provision for older adults have been poorly studied in relation to appetite control in the context of energy balance. This is important to consider since people eat foods, not nutrients, and food-based solutions should allow maintenance of the social and cultural aspects of eating wherever possible.

\section{APPETITE IN THE OLDER ADULT}

Appetite can be simply defined as the internal driving force for the search, choice, and ingestion of food. ${ }^{13}$ This can be assessed in two main ways. Firstly, subjective ratings can be used to record and rate subjects' motivation to eat over time, as is most commonly done using visual analogue rating scales. ${ }^{14}$ When used appropriately subjective ratings have been shown to be reproducible, sensitive to exposures of food components, and predictive of food intake in humans, albeit with limited data in an ageing population. Secondly, appetite can be measured by actual food intake, usually in a laboratory after a test meal. It is difficult to obtain a precise and valid estimate of energy intake on an individual level from dietary records alone as under-reporting and mis-reporting cannot be accounted for. These techniques should be conducted as a within-subject design to allow for a variety factors that may cause a mis-match between appetite and actual food intake. ${ }^{14}$ These include cognitive factors, such as dietary restraint, but also external factors, such as availability, hedonic food properties, and social circumstances. 
Although a great deal of research has studied the phenomenon of appetite, the mechanisms are still not entirely explored, particularly in response to ageing. ${ }^{15}$ In simple terms, hunger, satiation and appetite can be directly or indirectly stimulated by hormonal responses from:

i) pancreas, e.g. secretion of insulin, glucagon, pancreatic polypeptide (PP) and amylin;

ii) adipose tissue, e.g. leptin and adiponectin;

iii) gastrointestinal tract, e.g. ghrelin, glucagon-like peptide 1 and 2 (GLP-1, GLP-2), cholecystokinin (CKK), gastric inhibitory polypeptide (GIP), polypeptide YY (PYY), oxyntomodulin and serotonin;

iv) hypothalamus, e.g. dopamine, neuropeptide $Y$, growth hormone releasing peptide (GHRP). ${ }^{13,16}$

Some hormones or peptides promote appetite (orexigenic) and other work antagonistically, by suppressing it (anorexigenic). ${ }^{13,16}$ Apart from physiological factors, the sensorial exposure to food (e.g. sight, smell, taste) has been shown to increase appetite, although empirical data in elderly subjects is lacking. ${ }^{17}$ Lastly, a hierarchy has been observed for the satiating efficacies of the macronutrients protein, carbohydrate and fat, with protein being the most satiating and fat the least. A dose dependent satiating effect of protein has been shown, with quite a range of concentrations of protein offered acutely, in a single meal, to subjects who are in energy balance and weight stable. The mechanism that may contribute to protein-induced satiety are increases in (i) concentrations of the 'satiety' or hormones (GLP-1, CCK, PYY, ghrelin), (ii) energy expenditure, (iii) concentrations of metabolites, i.e. amino acids, and, (iv) the process of gluconeogenesis. ${ }^{13,16}$ This satiating efficiency of protein is useful for a weight loss scenario, where feeling full but eating less than energy requirements is prescribed, however, it is not useful if ageing subjects feel over-full when eating a protein rich meal and subsequently reduce food intake throughout the remainder of the day. This can be addressed by the amount and mode of delivery, as will be discussed. 
As we age, physiology and feeding behaviour change. Failure of older people to adequately regulate food and nutrient intake results in weight loss; and such changes have been termed the anorexia of ageing. ${ }^{18}$ Lack of adequate and balanced dietary intake leads to further adverse health consequences, including sarcopenia, protein-energy malnutrition, frailty, and increased morbidity and mortality. ${ }^{19}$ With such dramatic consequences, early identification and effective interventions for the anorexia of ageing are needed.

The etiology of the anorexia of ageing is multi-factorial and includes a range of symptoms across the satiety cascade - a series of behavioural and physiological events that occur following food intake that inhibit further eating until the return of hunger signals. Age related anorexia is characterized by several influences at each stage of the cascade. ${ }^{20,21}$ (Figure 1)

\section{$<$ Figure 1 near here $>$}

The anorexia of ageing is complicated and linked to other pathological conditions such as depression, dementia, somatic diseases, medications and iatrogenic interventions. Eating represents a form of behaviour as well as a means to satisfy hunger, so aside from physiological changes, changing social circumstances such as poverty, solitary dining and loneliness can impact on the reward factor of eating, which itself has a major influence on portion size. Therefore, food needs to be appealing and targeted for older people. ${ }^{22}$ Indeed, many neurobiological mechanisms may be secondary to age-related changes in body composition and not associated with anorexia per se, but there are currently no available management strategies to prevent or reverse the anorexia of ageing. 
Ageing is characterized by a blunted response of muscle protein synthesis following protein ingestion and a preponderance of evidence now points towards an age-related 'anabolic resistance' to protein feeding as one of the key factors underpinning sarcopenia. ${ }^{23}$ Strategies aiming at speeding-up protein digestion rate, changing daily protein feeding pattern, protein quality or, supplementing with specific amino acids may be beneficial to improve short-term anabolic response of muscle in elderly people.

From a nutrition perspective, incorporating more protein into the diet may be an intervention target for frailty prevention. Higher protein intakes are shown to decrease the risk of frailty, partly due to action on muscle mass. For example, in a prospective cohort study, 24,417 women aged 65-79 who were free of frailty at baseline were included. ${ }^{24}$ Baseline protein intake was estimated from the food frequency questionnaire. After 3 years of follow-up, 3298 women from the cohort developed frailty. High protein consumption, as a fraction of energy, was associated with a strong, independent, dose-responsive lower risk of incident frailty: a 20\% increase in calibrated protein intake was associated with a $32 \%$ lower risk of frailty. ${ }^{24}$ However, in a recent meta-analysis it was demonstrated that protein supplementation in older people is not associated with greater increases in muscle mass and strength, compared to control groups, in response to resistance exercise training..$^{25}$ This observation may be due to the timing of the protein consumption, with studies either supplementing with protein immediately before and after exercise, or at a time unrelated to the exercise; it is often erroneously thought that muscle is only sensitive to protein for a short period after exercise, when in fact this period is at least 24 hours..$^{26,27}$ Therefore, the timing of this protein dose in older people performing exercise may be important.

Throughout the day muscle protein synthesis and muscle protein breakdown are variable depending upon food consumption. The accretion or maintenance of muscle mass is determined by the balance between muscle protein synthesis (MPS) and muscle protein breakdown (MPB). For protein accretion and an increase in muscle mass to occur, MPS must 
be greater than MPB. Both exercise and nutrition influence muscle mass primarily through changes in MPS to a greater extent than MPB and so MPS is general accepted as being the dominant process regulating muscle mass. ${ }^{28}$ As protein consumption is necessary to allow protein accretion (via increases in MPS primarily) in response to resistance exercise it has been suggested that increasing protein intake will enhance the adaptive responses to resistance exercise in older people. ${ }^{29}$ Here lies a crucial factor for long-term health - patients do not eat nutrients, they eat food and meals that contribute to their diet quality and quantity.

\section{THE OPTIMAL TYPE OF SUPPLEMENTARY PROTEIN FOR OLDER ADULTS}

The provision of sufficient high nutritional value dietary proteins is central to muscle health as it ensures the bioavailability of essential amino acids for stimulating muscle protein synthesis. ${ }^{6}$ There is debate about the optimal source of protein and numerous quality assessment measures have been proposed. ${ }^{30}$ The most commonly applied method to assess protein quality involves the calculation of a Protein Digestibility Corrected Amino Acid (PDCAA) Score, or Digestibility Indispensable Amino Acid (DIAA) Score. ${ }^{31,32}$ In general, animal-based foods are recognised as a superior source of protein because they have a complete composition of essential amino acids, with high digestibility (>90\%) and bioavailability. ${ }^{33}$ Animal proteins have higher PDCAA scores than plants, suggesting greater efficiency in muscle anabolic processes. ${ }^{32}$ For example, proteins found in milk, whey, egg casein and beef have the highest score (1.0), while scores for plant-based proteins are as follows: soy (0.91), pea (0.67), oat (0.57) and whole wheat (0.45). ${ }^{32}$ However, proteins do not occur in foods in isolation and the entire food matrix should to be considered when health benefits are evaluated. ${ }^{30}$ Apart from protein, animal-based foods provide heme-iron, cholecalciferol, docosahexaenoic acid (DHA), vitamin B12, and recently studied creatinine, taurine, carnosine and conjugated linoleic acid (CLA); all compounds not present in plant-based foods. ${ }^{34}$ Thus, moderate consumption of high quality, unprocessed animal-based foods should not be entirely discouraged. 
Of all the essential amino acids, leucine has perhaps received the most attention since it has the property of maintaining protein retention by upregulating mRNA translation and increasing muscle protein synthesis. Longitudinal nutritional intervention studies exploring the effectiveness of leucine supplementation have presented mixed findings, but results from a small double-blind, placebo-controlled trial by Ispoglou et al were promising. ${ }^{35}$ They showed that twice daily supplementation of EAAs containing $20 \%$ or $40 \%$ L-leucine improved functional performance and lean tissue mass at the high level when combined with a diet with adequate protein and energy. According to PROT-AGE recommendations, 2.5-2.8 g of leucine per meal is sufficient to reach anabolic threshold and optimise MPS. ${ }^{9}$ This amino-acid is relatively abundant in certain plants, with the highest amounts found in dried seaweed $(4.95 \mathrm{~g} / 100 \mathrm{~g})$, dry-roasted soy beans $(3.22 / 100 \mathrm{~g})$, roasted pumpkin seeds $(2.39 \mathrm{~g} / 100 \mathrm{~g})$, dry-roasted peanuts $(1.53 \mathrm{~g} / 100 \mathrm{~g})$, cooked lentils $(1.29 \mathrm{~g} / 1$ cup) and barley flour (0.71g/100g). ${ }^{36}$

With reduced saliva and mastication capabilities, liquid-based foods can be helpful in maintaining nutritional status and muscle mass in the elderly without impacting on appetite for main meals. ${ }^{37}$ Commonly prescribed supplements are fortified milk based drinks, and these contain around 9g protein per serving. ${ }^{36}$ Benefits of such oral nutrition supplements are not restricted to energy alone, with a recent systematic review and meta-analysis suggesting that it could be that the additional dietary components (including protein, trace elements and vitamins) consumed as part of extra calories that is key to influencing improved nutritional outcomes..$^{38}$ The studies report that a significant reduction in hospital readmissions with the consumption of ready-made, multi-nutrient supplements, with the benefits mostly observed in older individuals. ${ }^{38}$ The authors further compared standard and high protein oral nutritional supplements but there was inadequate information to advise on clinical or cost effectiveness, and more evidence is required to support clinical guidelines. ${ }^{39}$ 
Apart from the total daily intake, per-meal protein quantity and daily frequency of protein ingestion have also been shown to play an important role in preserving muscle mass and function. ${ }^{40}$ The speed of absorption of dietary amino acids by the gut varies according to the type of ingested dietary protein and the presence of other macronutrients. ${ }^{41}$ The speed of absorption can affect postprandial (after meals) protein synthesis, breakdown, and deposition. It's been shown that the postprandial amino acid levels differ a lot depending on the mode of administration of a dietary protein; a single protein meal results in an acute but transient peak of amino acids whereas the same amount of the same protein given in a continuous manner, which mimics a slow absorption, induces a smaller but prolonged increase. ${ }^{40}$ Since amino acids are potent modulators of protein synthesis, breakdown, and oxidation, different patterns of postprandial aminoacidemia (the level of amino acids in the blood) might well result in different postprandial protein kinetics and gain, and also impact on satiety. This has recently been reviewed by Murton (2015) and Witard et al (2016). ${ }^{41,42}$ Therefore, the speed of absorption by the gut of amino acids derived from dietary proteins will have different effects on whole body protein synthesis, breakdown, and oxidation, which in turn control protein deposition. Casein is a slowly absorbed protein, likely to delay gastric emptying. Whey protein is a fast protein, introducing a short increase of plasma amino acids. The latter are ideal for an elderly study, where appetite may be poor and consumption of a protein drink should not impact (reduce) subsequent food intake. ${ }^{41}$ This is not a meal replacement, rather a 'supplement' to boost nutritional status. For example, a bedtime milk drink could hypothetically reduce negative protein balance, via increases in MPS and decreases in MPB, and may result in a positive protein balance throughout the day and ultimately enhance the adaptive responses to resistance exercise training, without impacting on food choice and appetite at the traditional eating episodes. $^{41}$

Older individuals therefore seem to require higher protein intake spread throughout the day to maximize the meal-induced anabolic response and to alleviate age-related decline in muscle mass. It is estimated that consumption of two to three meals a day, each containing $\sim 25-30 \mathrm{~g}$ of protein, is optimal for the stimulation of 24-h muscle protein synthesis (MPS) in healthy adults. ${ }^{43-47}$ Some studies argue that consuming a much higher dose of protein on one daily occasion (pulse feeding) can stimulate a higher anabolic response than smaller doses across multiple meals. ${ }^{48-50}$ Arnal and colleagues reported that women (mean age $68 \pm 1$ y) who consumed $\sim 80 \%$ of daily protein at noon during the trial had improved nitrogen balance, when compared to women who consumed the 
same amount of protein spread over four meals. ${ }^{48}$ However, the spread pattern tested in this study stipulates the risk, that none of the four meals contained the required bolus of 25-30 g protein per serving, resulting in this treatment being less effective. Reports by Bouillanne and colleagues were in line with Arnal's findings, suggesting that pulse feeding was more effective in improving lean mass index in hospitalised patients at risk of malnutrition (mean age 84.1 y).49,50

An uneven pattern of protein ingestion is commonly observed among ageing adults inferring a risk of insufficient stimulation of MPS, even when RDA is being met on a daily basis. It is interesting that the Newcastle $85+$ study revealed, that the highest amount of protein in this UK-based cohort was consumed at lunch time, accounting for $~ 35 \%$ (around $20 \mathrm{~g}$ ) of daily protein intake, with the least at breakfast time. ${ }^{51}$ This means that the stimulation with a meal containing $\sim 25-30$ g of protein occurs only once a day, during the mid-day meal. As suggested by Bollwein et al, protein distribution at older age is of higher importance than the total daily amount per se. In his study, the recommendation of $0.8 \mathrm{~g} / \mathrm{kg} / \mathrm{bw}$ was exceeded by all participants (> $75 \mathrm{y}$ ), even those from the lowest quartile of protein intake. No differences were observed between frailty status and daily protein intake. However, those with more uneven distribution were most prevalent in the frail group, characterised by lower walking speed and higher exhaustion..$^{52}$ Because the ingestion of high-protein meal before sleep has been shown to increase overnight MPS, this dietary habit should be sustained. ${ }^{53}$ In addition, to stimulate 24-hour MPS, enriching the content of remaining meals with high-quality protein should be strongly encouraged, to ensure sufficient dose of protein in each meal.

\section{CONCLUSION}

With nutrition undoubtedly playing a key role in maintaining QOL, it is key that clinicians make a careful assessment of the nutritional status of the ageing patient and consider protein-rich supplementation at an early stage. Designing foods for specific situations like in elderly patients with poor appetite, may modulate the pathophysiological processes leading to muscle loss. Recent evidence also indicates that a multimodal approach combining nutrition, exercise, hormones, and 
specific drugs may be a more appropriate treatment for limiting the development of sarcopenia with aging. Key foci of ongoing research should be to provide robust evidence from trials in older adults to help define the optimum type and timing of dietary supplements, especially protein.

Words: 3103

Funding: None

Conflict of Interest: None 
1. BAPEN. The cost of malnutrition in england and potential cost savings from nutritional interventions. https://www.bapen.org.uk/pdfs/economic-report-short.pdf. Updated 2015. Accessed 11th June, 2018.

2. Patel HP, Syddall HE, Jameson K, et al. Prevalence of sarcopenia in community-dwelling older people in the UK using the european working group on sarcopenia in older people (EWGSOP) definition: Findings from the hertfordshire cohort study (HCS). Age Ageing. 2013;42(3):378-384.

3. Wolfe RR. The underappreciated role of muscle in health and disease. Am J Clin Nutr. 2006;84(3):475-482.

4. Pannemans DL, Halliday D, Westerterp KR, Kester AD. Effect of variable protein intake on whole-body protein turnover in young men and women. Am J Clin Nutr. 1995;61(1):69-74.

5. Starling RD, Poehlman ET. Assessment of energy requirements in elderly populations. Eur J Clin Nutr. 2000;54 Suppl 3:S104-11.

6. World Health Organization. Protein and amino acid requirements in human nutrition. report of a joint FAO/WHO/UNU expert consultation (WHO technical report series 935). . 2007.

7. Campbell WW, Trappe TA, Wolfe RR, Evans WJ. The recommended dietary allowance for protein may not be adequate for older people to maintain skeletal muscle. J Gerontol A Biol Sci Med Sci. 2001;56(6):M373-80. 
8. Wolfe RR, Miller SL, Miller KB. Optimal protein intake in the elderly. Clin Nutr. 2008;27(5):675-684.

9. Bauer J, Biolo G, Cederholm T, et al. Evidence-based recommendations for optimal dietary protein intake in old. J Am Med Dir Assoc. 2013;14(8):542-559.

10. Deutz NE, Bauer JM, Barazzoni R, et al. Protein intake and exercise for optimal muscle function with aging: Recommendations from the ESPEN expert group. Clin Nutr. 2014;33(6):929-936

11. Phillips SM, Chevalier S, Leidy HJ. Protein "requirements" beyond the RDA: Implications for optimizing health. Appl Physiol Nutr Metab. 2016;41(5):565-572.

12. Houston DK, Nicklas BJ, Ding J, et al. Dietary protein intake is associated with lean mass change in older, community-dwelling adults: The health, aging, and body composition (health ABC) study. Am J Clin Nutr. 2008;87(1):150-155.

13. de Graaf C, Blom WA, Smeets PA, Stafleu A, Hendriks HF. Biomarkers of satiation and satiety. Am J Clin Nutr. 2004;79(6):946-961.

14. Flint A, Raben A, Blundell JE, Astrup A. Reproducibility, power and validity of visual analogue scales in assessment of appetite sensations in single test meal studies. Int J Obes Relat Metab Disord. 2000;24(1):38-48.

15. Mercer JG, Johnstone AM, Halford JC. Approaches to influencing food choice across the age groups: From children to the elderly. Proc Nutr Soc. 2015;74(2):149-157. 
16. Suzuki K, Jayasena CN, Bloom SR. The gut hormones in appetite regulation. J Obes. $2011 ; 2011: 528401$.

17. Sorensen LB, Moller P, Flint A, Martens M, Raben A. Effect of sensory perception of foods on appetite and food intake: A review of studies on humans. Int J Obes Relat Metab Disord. $2003 ; 27(10): 1152-1166$.

18. Wysokinski A, Sobow T, Kloszewska I, Kostka T. Mechanisms of the anorexia of aging-a review. Age (Dordr). 2015;37(4):9821-015-9821-x. Epub 2015 Aug 1.

19. Visvanathan R. Anorexia of aging. Clin Geriatr Med. 2015;31(3):417-427.

20. Soenen S, Rayner CK, Horowitz M, Jones KL. Gastric emptying in the elderly. Clin Geriatr Med. 2015;31(3):339-353.

21. Smeets PA, Erkner A, de Graaf C. Cephalic phase responses and appetite. Nutr Rev. 2010;68(11):643-655.

22. Stevenson EJ, Watson AW, Brunstrom JM, et al. Protein for life: Towards a focussed dietary framework for healthy ageing. Nutr Bull. 2018;43(1):97-102.

23. Landi $F$, Calvani $R$, Tosato $M$, et al. Protein intake and muscle health in old age: From biological plausibility to clinical evidence. Nutrients. 2016;8(5):10.3390/nu8050295.

24. Beasley JM, LaCroix AZ, Neuhouser ML, et al. Protein intake and incident frailty in the women's health initiative observational study. J Am Geriatr Soc. 2010;58(6):1063-1071. 
25. Finger D, Goltz FR, Umpierre D, Meyer E, Rosa LH, Schneider CD. Effects of protein supplementation in older adults undergoing resistance training: A systematic review and meta-analysis. Sports Med. 2015;45(2):245-255.

26. Burd NA, West DW, Staples AW, et al. Low-load high volume resistance exercise stimulates muscle protein synthesis more than high-load low volume resistance exercise in young men. PLoS One. 2010;5(8):e12033.

27. Tieland M, Borgonjen-Van den Berg KJ, Van Loon LJ, de Groot LC. Dietary protein intake in dutch elderly people: A focus on protein sources. Nutrients. 2015;7(12):9697-9706.

28. Glynn EL, Fry CS, Drummond MJ, et al. Muscle protein breakdown has a minor role in the protein anabolic response to essential amino acid and carbohydrate intake following resistance exercise. Am J Physiol Regul Integr Comp Physiol. 2010;299(2):R533-40.

29. Tipton KD, Ferrando AA, Phillips SM, Doyle D,Jr, Wolfe RR. Postexercise net protein synthesis in human muscle from orally administered amino acids. Am J Physiol. 1999;276(4 Pt 1):E628-34.

30. Millward DJ. Methodological considerations. Proc Nutr Soc. 2001;60(1):3-5.

31. Schaafsma G. Advantages and limitations of the protein digestibility-corrected amino acid score (PDCAAS) as a method for evaluating protein quality in human diets. Br J Nutr. 2012;108 Suppl 2:S333-6.

32. van Vliet S, Burd NA, van Loon LJ. The skeletal muscle anabolic response to plant- versus animal-based protein consumption. J Nutr. 2015;145(9):1981-1991. 
33. Food and Nutrition Board of the Institute of Medicine. Dietary reference intakes for energy, carbohydrate, fibre, fat, fatty acids, cholesterol, protein and amino acids (macronutrients). . 2005.

34. Olmedilla-Alonso B, Jimenez-Colmenero F, Sanchez-Muniz FJ. Development and assessment of healthy properties of meat and meat products designed as functional foods. Meat Sci. 2013;95(4):919-930.

35. Ispoglou T, Deighton K, King RF, White H, Lees M. Novel essential amino acid supplements enriched with L-leucine facilitate increased protein and energy intakes in older women: A randomised controlled trial. Nutr J. 2017;16(1):75-017-0298-6.

36. United States Department of Agriculture. Agricultural Research Service. USDA food composition databases. https://ndb.nal.usda.gov/ndb/. Updated 2018. Accessed November 14, 2017.

37. Paddon-Jones D, Leidy H. Dietary protein and muscle in older persons. Curr Opin Clin Nutr Metab Care. 2014;17(1):5-11.

38. Stratton RJ, Hebuterne X, Elia M. A systematic review and meta-analysis of the impact of oral nutritional supplements on hospital readmissions. Ageing Res Rev. 2013;12(4):884-897.

39. Cawood AL, Elia M, Stratton RJ. Systematic review and meta-analysis of the effects of high protein oral nutritional supplements. Ageing Res Rev. 2012;11(2):278-296.

40. Murphy $\mathrm{CH}$, Oikawa SY, Phillips SM. Dietary protein to maintain muscle mass in aging: A case for per-meal protein recommendations. J Frailty Aging. 2016;5(1):49-58. 
41. Witard OC, McGlory C, Hamilton DL, Phillips SM. Growing older with health and vitality: A nexus of physical activity, exercise and nutrition. Biogerontology. 2016;17(3):529-546.

42. Murton AJ. Muscle protein turnover in the elderly and its potential contribution to the development of sarcopenia. Proc Nutr Soc. 2015;74(4):387-396.

43. Paddon-Jones D, Rasmussen BB. Dietary protein recommendations and the prevention of sarcopenia. Curr Opin Clin Nutr Metab Care. 2009;12(1):86-90.

44. Symons TB, Sheffield-Moore M, Wolfe RR, Paddon-Jones D. A moderate serving of highquality protein maximally stimulates skeletal muscle protein synthesis in young and elderly subjects. J Am Diet Assoc. 2009;109(9):1582-1586.

45. Mamerow MM, Mettler JA, English KL, et al. Dietary protein distribution positively influences 24-h muscle protein synthesis in healthy adults. J Nutr. 2014;144(6):876-880.

46. Loenneke JP, Loprinzi PD, Murphy CH, Phillips SM. Per meal dose and frequency of protein consumption is associated with lean mass and muscle performance. Clin Nutr. 2016;35(6):1506-1511.

47. Farsijani S, Payette H, Morais JA, Shatenstein B, Gaudreau P, Chevalier S. Even mealtime distribution of protein intake is associated with greater muscle strength, but not with 3-y physical function decline, in free-living older adults: The quebec longitudinal study on nutrition as a determinant of successful aging (NuAge study). Am J Clin Nutr. 2017;106(1):113-124. 
48. Arnal MA, Mosoni L, Boirie $\mathrm{Y}$, et al. Protein pulse feeding improves protein retention in elderly women. Am J Clin Nutr. 1999;69(6):1202-1208.

49. Bouillanne $\mathrm{O}$, Curis $\mathrm{E}$, Hamon-Vilcot $\mathrm{B}$, et al. Impact of protein pulse feeding on lean mass in malnourished and at-risk hospitalized elderly patients: A randomized controlled trial. Clin Nutr. 2013;32(2):186-192.

50. Bouillanne O, Neveux N, Nicolis I, Curis E, Cynober L, Aussel C. Long-lasting improved amino acid bioavailability associated with protein pulse feeding in hospitalized elderly patients: A randomized controlled trial. Nutrition. 2014;30(5):544-550.

51. Mendonca N, Granic A, Mathers JC, et al. Prevalence and determinants of low protein intake in very old adults: Insights from the newcastle 85+ study. Eur J Nutr. 2017.

52. Bollwein J, Diekmann R, Kaiser MJ, et al. Distribution but not amount of protein intake is associated with frailty: A cross-sectional investigation in the region of nurnberg. Nutr J. 2013;12:109-2891-12-109.

53. Kouw IW, Holwerda AM, Trommelen J, et al. Protein ingestion before sleep increases overnight muscle protein synthesis rates in healthy older men: A randomized controlled trial. J Nutr. 2017;147(12):2252-2261. 